\title{
EJNSO
}

\section{Submucosal Diathermy Versus Coblation For Reduction of Hypertrophied Inferior Turbinate}

\author{
Mohamed A. M. Salem ${ }^{1}$, Mostafa Hefzy Hassanin ${ }^{2}$, Ezzat Mohamed Saleh Kayed ${ }^{1}$ \\ 1. Department of Otorhinolaryngology -Head and Neck Surgery, Faculty of Medicine- Assiut \\ University. \\ 2. Department of Otorhinolaryngology-Head and Neck Surgery, Assiut police Hospital
}

\begin{abstract}
Background: Nasal obstruction is the foremost complaint of a large number of patients in otolaryngologic practice. Most of those patients have inferior turbinate hypertrophy. Surgery is one of the modalities of treatment to relieve patients of nasal obstruction. The objective of this study was to evaluate the efficacy of submucosal diathermy (SMD) and coblation in the treatment of hypertrophied inferior turbinate.

Materials and methods: The study included 30 consecutive adult patients with bilateral inferior turbinate hypertrophy, all patients underwent SMD in the right side and coblation in the left side by using the same device (coblator II, Arthrocare, USA). They were assessed for relief of variable nasal symptoms by subjective and objective methods.

Results: According to the results obtained from this study, nasal obstruction improved significantly by both techniques, but more improvement was observed in the side treated by coblation, and coblation was less painful during the procedure and in the post-operative period. Both of the two techniques reduce the hypertrophied inferior turbinate significantly . Conclusions: Both SMD and Coblation of the inferior turbinate are safe and effective methods of relieving nasal obstruction and other associated symptoms due to inferior turbinate hypertrophy, without affecting the turbinate mucosal function.
\end{abstract}

Keywords: Inferior turbinate, hypertrophy, coblation, submucosal diathermy.

\section{Introduction:}

Nasal obstruction is the foremost complaint of a large number of patients in otolaryngologic practice most commonly caused by inferior turbinate hypertrophy. It can cause a significant discomfort. ${ }^{1}$

Inferior turbinate hypertrophy can result from mucosal hypertrophy, elongated bony hypertrophy or both which causes a fixed structural obstruction and causing impingement on the nasal valve, increasing nasal resistance. $^{2}$

Medical treatment includes nasal drops, antihistaminics, topical and systemic steroids. Surgery is necessary in many cases. A variety of surgical procedures have been described for reduction of hypertrophied inferior turbinate. $^{3}$

When coblation is being used to perform surgery the interface between plasma and dissected tissue acts as a gate for charged particles. The effect of plasma on tissue is purely chemical and not thermal. Plasma generates $\mathrm{H}$ and $\mathrm{OH}$ ions. These ions make plasma destructive. $\mathrm{OH}$ radical causes protein degradation. Coblation causes low temperature molecular disintegration. 
This causes volumetric removal of tissue with minimal damage to adjacent tissue. ${ }^{4}$

Radiofrequency, patients benefit the advantage of that no nasal pack is required, only minimal postoperative pain which requires mild analgesics and they are discharged one hour after treatment and can return immediately to normal activity. ${ }^{5}$

Submucosal electrocautery is delivered along the vascular layer and current is concentrated around the exposed tip producing a localized response. The extent of the coagulation is determined by the magnitude of the current and the duration of exposure at any particular point. ${ }^{6}$

Regeneration of cilia in turbinate mucosal surface was not observed after using SMD. The respiratory epithelium was degenerated and transformed to flattened stratified. Histological changes involving transformation of columnar epithelium into cuboidal or squamous epithelium due to burn injury. ${ }^{7}$ The aim of the present study is to compare the effectiveness and safety of SMD and coblation in the reduction of hypertrophied inferior turbinate.

\section{Patients and Methods:}

\section{Patients:}

This study is an observational randomized comparative clinical trial. It was done after approval of the ethical committee on $29 / 10 / 2015$. The study included 30 consecutive adult candidates for turbinate reduction caused by bilateral inferior turbinate hypertrophy. The patients were recruited from the outpatient ENT clinic of Assiut University Hospital from December 2015 to May 2017.

\section{Inclusion criteria:}

Adult patients with bilateral inferior turbinate hypertrophy.

\section{Exclusion criteria:}

-Patients who had previous nasal or sinus surgery
- Causes of nasal obstruction other than turbinate hypertrophy such as nasal septum deviation, rhinitis, granulomas and nasal polyposis

-Patients with systemic diseases that contraindicate surgery.

\section{Methods:}

Preoperative evaluation:

All patients in this study were subjected to:

1. Detailed history all patients were complaining from nasal obstruction. Other symptoms that were present in some patients include rhinorrhea, sneezing, itchy nose, snoring, headache and smell disorder(hyposmia).

2. Nasal examination revealed bilateral inferior turbinate hypertrophy.

3. Endoscopic examination using 0degree, $4 \mathrm{~mm}$ sinoscope (Karl storz, Germany).

4. Radiological examination: was done to all patients. coronal, sagittal and axial sections $2 \mathrm{~mm}$ cuts were done to diagnose hypertrophy of inferior turbinate and exclude other causes of nasal obstruction as nasal septum deviation, granulomas and nasal polyposis. For inferior turbinate size in $(\mathrm{mm})$ measured at the widest diameter and it was reevaluated 2 months postoperative.

\section{Surgery:}

The procedure was done under general anesthesia with orotracheal intubation and endoscopic guide. The patients were in supine position.

Precautions were done to avoid burns and accidents during surgery. We applied cotton pledged soaked in 3\% ephedrine to differentiate between mucosal and bony hypertrophy.

By using the same device (coblator II, Arthrocare, USA); as two settings are set i.e. coblation and cauterization and switched between them through a foot 
pedal control which has two color coded pedals. Yellow one is for coblation and the blue one is for cautery. The system was set to power level of 6 . The probe was inserted in the submucosal plane and it is marked at 3 symmetric locations roughly 1 centimeter apart. Beginning posteriorly and moving anteriorly, the probe was then activated for 30 seconds at each location. Fig. (1).

Nasal pack was applied in the nasal cavity bilaterally when needed and removed one day postoperative.



Fig. (1): Probe of coblator II

\section{Postoperative Follow-up:}

The patients were subjected to postoperative follow up for at least 2 months every week in the first month then every 2 weeks and it included fulfilling these items:

\section{A. Subjective findings}

-Improvement of nasal obstruction.

-Disappearance of snoring.

-Improvement of post-operative pain.

-Improvement of smell.

For evaluation of postoperative pain, we used Guttman scale ${ }^{8}$ : It classifies pain according to intensity and disability into 4 classes: -

- Grade I: low intensity-low disability.

- Grade II: low disability-high intensity.

- Grade III: high intensity-moderately limiting.

- Grade IV: high disability-severely limiting.

Nasal obstruction was analyzed according to VAS (visual analogue scale) system ${ }^{9}$ by asking the patients to score relief of nasal obstruction postoperatively from 1-10 and were categorized as follow: -

-No improvement: VAS (1-3)

-Partial improvement: VAS (4-7).

-Complete improvement: VAS (8-10).

VAS scale was used to evaluate smell disorder (hyposmia): A visual analogue scale (VAS) was used to measure the difficulty in testing the smell. This consisted of a $100 \mathrm{~mm}$ line with no marks onto which subjects placed a vertical line to indicate the difficulty they encountered when taking the test; easy was toward the left and difficult was towards the right of the line. ${ }^{10}$

\section{B. Objective findings}

1- Nasal examination using sinoscope (Karl storz $4 \mathrm{~mm}$ ) to observe the size of turbinates, granulation tissue, infection, crustation and bleeding.

2- Radiological examination by CT was done 2 months post-operative to compare the size of inferior turbinate pre and postoperative.

\section{Statistical analysis:}

The statistical analysis was performed using SPSS 22.0 statistical package for the social sciences. pearsonchi_square test was used in analysis of the qualitative variables and the student test was used for the continuous variables.

Mann-Whitney Test was used to compare between coblation and SMD. Wilcoxon Signed Ranks Test was used to compare between pre-operative and post-operative.

$\mathrm{P}$ values $<0.05$ is considered statistically significant.

\section{Results:}

Thirty patients with bilateral hypertrophied inferior turbinate were included in this study. They were 21 males $(70.0 \%)$ and 9 females $(30.0 \%)$ and their ages ranged from 16 to 41 years and the mean age was 29 . 
Pre-operative symptoms: - Table (1) summarized the symptoms of patients included.

\begin{tabular}{|l|c|c|}
\hline Symptom & No. & Percentage \\
\hline Nasal obstruction & 30 & $100 \%$ \\
\hline Snoring & 21 & $70 \%$ \\
\hline Hyposmia & 30 & $100 \%$ \\
\hline Headache & 18 & $60 \%$ \\
\hline Rhinorrhea & 22 & $73.30 \%$ \\
\hline
\end{tabular}

\section{Post-operative pain:}

Post-operative pain was recorded by Guttman scale. In patients treated with SMD, after one-week Grade II recorded in 18 patients $(60 \%)$ but it regressed after two weeks to Grade I in 15 patients $(50 \%)$ and the rest were free of pain. Finally, after one month in 11 patients $(36.7 \%)$ it was Grade I, and 19 patients $(63.3 \%)$ were free of pain.

As for coblation post-operative pain which was recorded by Guttman scale. After one-week Grade I was recorded in 21 patients $(70 \%)$ but after two weeks 19 patients $(63.3 \%)$ were free of pain and finally after one month it was Grade $\mathrm{I}$ in 4 patients $(13.3 \%)$ and the 26 patients $(86.7 \%)$ were free of pain.

Comparing between both techniques there was a significant difference specially for coblation with $\mathrm{P}$-Value (0.0037). Fig. (2).



Fig. (2) Histogram shows post-operative pain

\section{Post-operative crustation:}

Post-operative crustation was recorded in 6 patients treated with SMD, while in patients treated with coblation, it was recorded in 4 patients only. So, there is no significant difference between the two techniques as regard post-operative crustation with $\mathrm{P}$-Value (0.488). Table (2).

\section{Post-operative bleeding:}

Post-operative bleeding was recorded in 6 patients treated with SMD, and it was recorded in 3 propatients treated with coblation, so there was no significant difference between the two techniques as regard post-operative bleeding with P-Value (0.472). Table (2).

\section{Snoring:}

Comparison between the two techniques cannot be assessed, but in general, snoring was positive in 21 patients $(70 \%)$ pre-operatively, but postoperative it was positive in 6 patients only and the rest of the patients were free of snoring with P-Value (0.000) which was significant.

\section{Nasal obstruction:}

Nasal obstruction was recorded by VAS scale for coblation; pre-operative mean was $7.70 \pm 0.47$ while postoperative mean was $1.20 \pm 0.41$ with $\mathrm{P}$ Value (0.001).

Nasal obstruction was recorded by VAS scale for SMD; pre-operative mean was $7.60 \pm 0.50$ while post-operative mean was $1.77 \pm 1.01$ with $\mathrm{P}$-Value (0.001).

There was a significant difference for coblation over SMD as regard nasal obstruction with P-value (0.014). Table (3) and Fig. (3, 5 and 6). 




Fig. (3) Histogram shows nasal obstruction pre and post-operative for both groups.

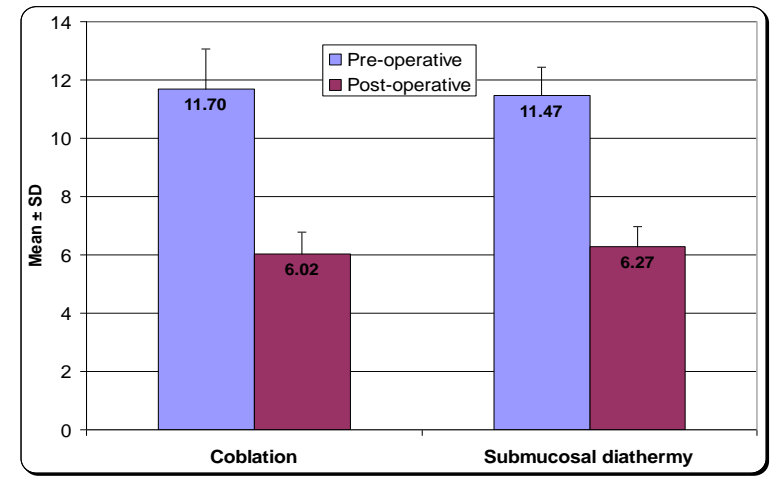

Fig. (4) Histogram shows the size of inferior turbinate in $\mathrm{CT}$ pre and postoperative.

\section{Smell disorders:}

The only smell disorder was hyposmia which was recorded by VAS scale. Hyposmia improved in 6 patients treated with coblation, worsened in 4 patients, while 20 patients did not change with $\mathrm{P}$ Value (0.052). Table (4).

It improved in 4 patients treated with SMD, worsened in 6 patients and did not change in 20 patients with P-value (0.310). Table (4).

There was no significant difference as regard hyposmia between the groups with P-Value (0.802).

\section{Inferior turbinate size by CT:}

Inferior turbinate size by $\mathrm{CT}$ in the side treated with coblation, pre-operative mean was $11.70 \pm 1.35 \mathrm{~mm}$ and postoperative mean $6.02 \pm 0.75 \mathrm{~mm}$ with $\mathrm{P}$ Value (0.001).

And for SMD, pre-operative mean was $11.47 \pm 0.98$ and post-operative mean $6.27 \pm 0.69$ with P-Value (0.001).

Comparing between the two techniques in reducing the size of inferior turbinate radiologically, there was no significant difference with $\mathrm{P}$ Value (0.198). But both of them reduced the size of inferior turbinate obviously. Table (5) and Fig. (4 and 7) 
Table (2): Post-operative complications:

\begin{tabular}{|c|c|c|c|c|c|}
\hline & \multicolumn{2}{|c|}{$\begin{array}{c}\text { Coblation } \\
(\mathbf{n}=30)\end{array}$} & \multicolumn{2}{|c|}{$\begin{array}{l}\text { Submucosal diathermy } \\
(n=30)\end{array}$} & \multirow[t]{2}{*}{ P-value } \\
\hline & No. & $\%$ & No. & $\%$ & \\
\hline \multicolumn{5}{|c|}{$\begin{array}{c}\text { Pain at } 1^{\text {st }} \text { month post- } \\
\text { operative }\end{array}$} & \multirow{4}{*}{$0.037 *$} \\
\hline No pain & 26 & 86.7 & 19 & 63.3 & \\
\hline Grade I & 4 & 13.3 & 11 & 36.7 & \\
\hline Grade II & 0 & 0.0 & 0 & 0.0 & \\
\hline \multicolumn{5}{|c|}{ Crustation: } & \multirow{3}{*}{0.488} \\
\hline Positive & 4 & 13.3 & 6 & 20.0 & \\
\hline Negative & 26 & 86.7 & 24 & 80.0 & \\
\hline \multicolumn{5}{|c|}{ Bleeding(2ry): } & \multirow{3}{*}{0.472} \\
\hline Positive & 3 & 10.0 & 6 & 20.0 & \\
\hline Negative & 27 & 90.0 & 24 & 80.0 & \\
\hline
\end{tabular}

Table (3): Nasal Obstruction:

\begin{tabular}{|c|c|c|c|}
\hline Obstruction & $\begin{array}{c}\text { Coblation } \\
(\mathbf{n}=\mathbf{3 0})\end{array}$ & $\begin{array}{c}\text { Submucosal } \\
\text { diathermy } \\
(n=30)\end{array}$ & P-value \\
\hline Pre-operative & & & \multirow{3}{*}{0.421} \\
\hline Mean \pm SD & $7.70 \pm 0.47$ & $7.60 \pm 0.50$ & \\
\hline Range & $7.0-8.0$ & $7.0-8.0$ & \\
\hline Post-operative & & & \multirow{3}{*}{$0.014 *$} \\
\hline Mean \pm SD & $1.20 \pm 0.41$ & $1.77 \pm 1.01$ & \\
\hline Range & $1.0-2.0$ & $1.0-4.0$ & \\
\hline P-value ${ }^{2}$ & $0.001 *$ & $0.001 *$ & \\
\hline
\end{tabular}

1: Comparison between Coblation and Submucosal diathermy (Mann-Whitney Test).

2: Comparison between Pre-operative and Post-operative (Wilcoxon Signed Ranks Test).

* Statistically significant difference $(\mathrm{P}<0.05)$.

Table (4): Smell disorder (Hyposmia):

\begin{tabular}{|c|c|c|c|}
\hline Smell disorder (Hyposmia) & $\begin{array}{c}\text { Coblation } \\
(\mathbf{n = 3 0})\end{array}$ & $\begin{array}{c}\text { Submucosal } \\
\text { diathermy } \\
(\mathbf{n = 3 0})\end{array}$ & \multirow{2}{*}{ P-value $^{\mathbf{3}}$} \\
\cline { 1 - 3 } Pre-operative: & $7.13 \pm 2.08$ & $7.10 \pm 2.14$ & \multirow{2}{*}{0.987} \\
\hline Mean \pm SD & $2.0-10.0$ & $2.0-10.0$ & \multirow{2}{*}{0.802} \\
\hline Range & & & \\
\hline Post-operative: & $6.47 \pm 2.33$ & $6.73 \pm 2.13$ & \\
\hline Mean \pm SD & $2.0-10.0$ & $2.0-10.0$ & \\
\hline Range & 0.052 & 0.310 & \\
\hline P-value & & &
\end{tabular}

1: Comparison between Coblation and Submucosal diathermy (Mann-Whitney Test).

2: Comparison between Pre-operative and Post-operative (Wilcoxon Signed Ranks Test).

* Statistically significant difference $(\mathrm{P}<0.05)$. 
Table (5): Turbinate size in $\mathrm{mm}$ by CT:

\begin{tabular}{|c|c|c|c|}
\hline $\begin{array}{c}\text { Turbinate size in mm } \\
\text { Two months post-op. }\end{array}$ & $\begin{array}{c}\text { Coblation } \\
(\mathbf{n}=\mathbf{3 0})\end{array}$ & $\begin{array}{c}\text { Submucosal } \\
\text { diathermy } \\
(\mathbf{n}=\mathbf{3 0})\end{array}$ & \multirow{2}{*}{ P-value $^{\mathbf{1}}$} \\
\cline { 1 - 3 } Pre-operative: & $11.70 \pm 1.35$ & $11.47 \pm 0.98$ & \multirow{2}{*}{0.456} \\
\hline Mean \pm SD & $10.0-14.0$ & $10.0-13.0$ & \multirow{2}{*}{0.198} \\
\hline Range & $6.02 \pm 0.75$ & $6.27 \pm 0.69$ & \\
\hline Post-operative: & $5.0-7.0$ & $5.0-7.0$ & \\
\hline Mean \pm SD & $0.001^{*}$ & $0.001^{*}$ & \\
\hline Range & P-value $^{2}$ & &
\end{tabular}

1: Comparison between Coblation and Submucosal diathermy (Mann-Whitney Test).

2: Comparison between Pre-operative and Post-operative (Wilcoxon Signed Ranks Test).

* Statistically significant difference $(\mathrm{P}<0.05)$.
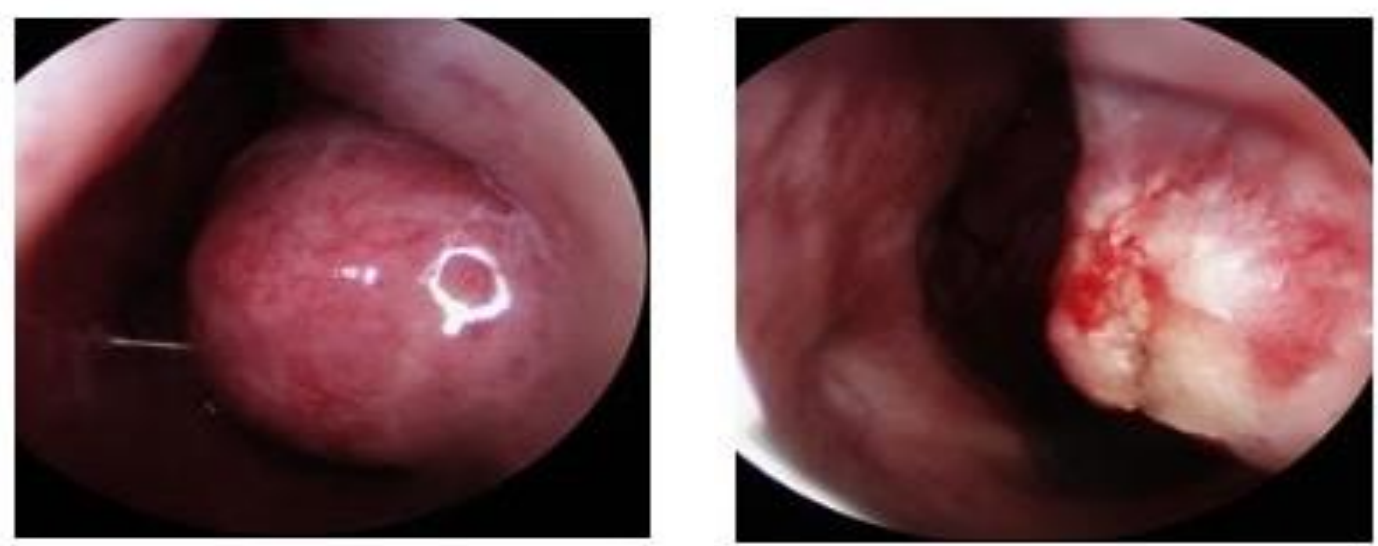

Fig. (5): Endoscopic picture of left inferior turbinate (a) before coblation (b) immediately after coblation demonstrating marked reduction in the inferior turbinate size.
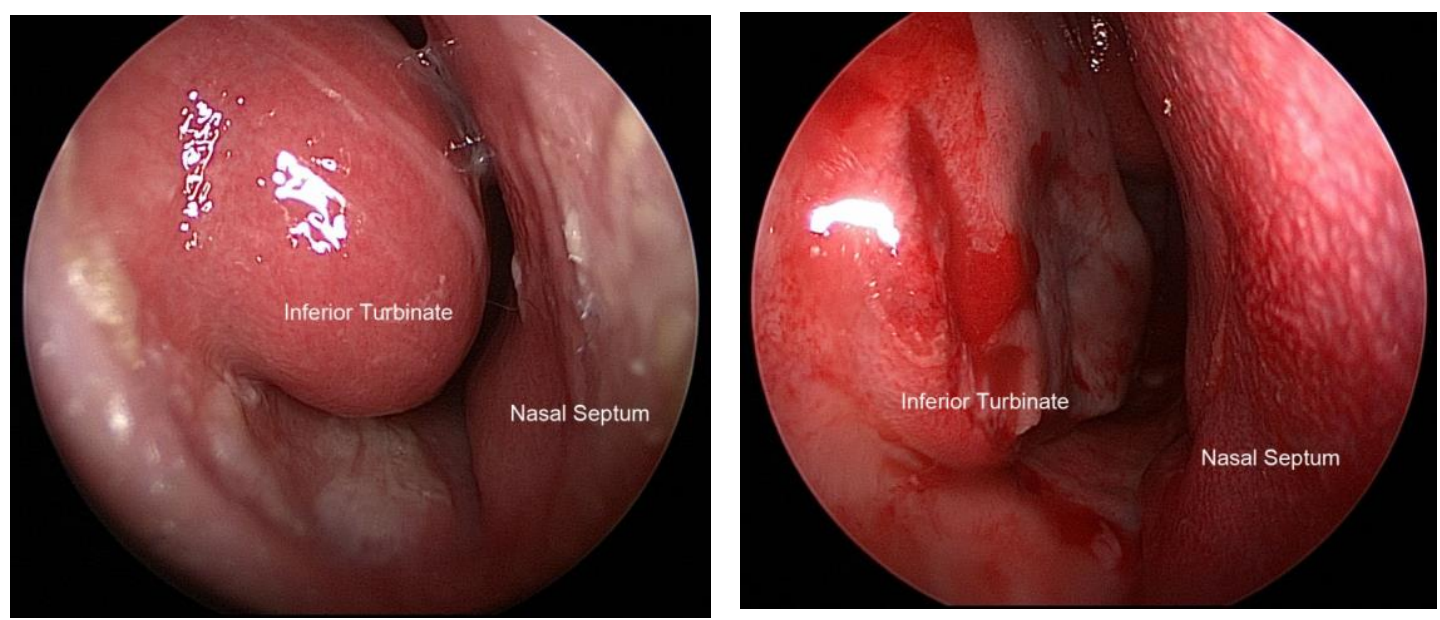

Fig. (6): Endoscopic picture of right inferior turbinate (a) before SMD\&(B) after SMD demonstrating marked reduction in the inferior turbinate size. 

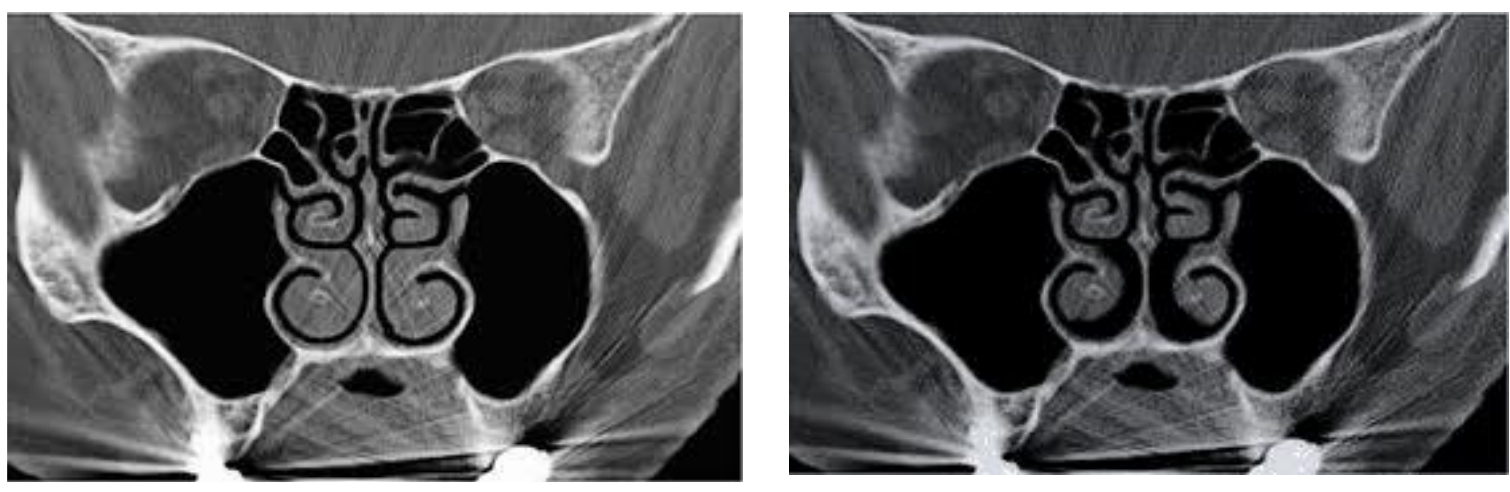

Fig. (7) Coronal CT a) Preoperative and (b) postoperative demonstrating marked reduction of the inferior turbinate size.

\section{Discussion :}

Various types of turbinate surgery are commonly used for treatment of nasal obstruction, but the best method is still a matter of controversy. Submucosal techniques have advantages in terms of preserving overall nasal physiology, because they act by destroying some of the large cavernous blood spaces or sinusoids of the inferior nasal turbinate, leading thus to shrinkage of its mucous membrane. This initiates the formation of fibrous tissue anchoring the mucosa to the periosteum. ${ }^{11}$

RF creates ionic igitation in the tissue, inducing submucosal necrosis. The resultant fibrosis of the submucosa adheres the mucosa to the turbinate periosteum, reducing the blood flow to the turbinate. Resultant wound contraction causes volume reduction of the inferior turbinate without damage to the overlying mucosa. The target temperature can be controlled at $60-90 \mathrm{c}$ to prevent surrounding tissue damage. ${ }^{2}$

This prospective study aimed at comparison between SMD and coblation in reduction of hypertrophied inferior turbinate and to be followed up for 2 months included 30 patients (21 male and 9 female), their ages ranged between 16-41 years (mean age 29 years).

In our study nasal obstruction improved obviously by both techniques (coblation and SMD) but more in coblation that showed significant difference with p-value (0.014). Our results are close to the results of the prospective study, Shah et al (2015) ,which reported that both interventions were similar in subjective and objective improvements in nasal obstruction. ${ }^{12}$

Nasal obstruction improved in both sides post-operatively than preoperatively and this is statistically significant table (5).

In this study we found that there was a significant improvement in snoring which was present in 21 of the 30 patients preoperatively and improved in 15 patients of them with p-value (0.000). These results are close to results reported by Casale et al (2014) $)^{13}$ who noted that all patients had significant improvement in nasal breathing and snoring which evaluated by VAS scale. Comparing our results with the results of Casale et al (2014) $)^{13}$, they found that all patients had significant improvement of snoring $(5.62 \pm 2.80$ versus $1.86 \pm 1.43$, $\mathrm{p}<0.001)$ with a mean snoring VAS improvement of $77.4 \%$, while our study showed that snoring improved in $71.4 \%$ with p-value (0.000).

Postoperative bleeding for coblation presented in 3 patients $(10 \%)$ and for SMD in 6 patients $(20 \%)$ and there was 
no uncontrolled bleeding. The results are in agreement with the results of Salzano et al (2009) ${ }^{14}$ who reported that postoperative bleeding for both SMD and coblation was $9.99 \%$.

Postoperative crustation after coblation occurred in 4 patients only $(13.3 \%)$ and for SMD occurred in 6 patients (20\%), while Salzano et al $(2009)^{14}$ found crustation after SMD in $60 \%$ patients and crustation not present after coblation.

We found that coblation less painful than SMD in the postoperative period as measured by Guttman scale, we found that for coblation 26 patients $(86.7 \%)$ were free of pain and only 4 patients (13.3\%) reported grade I, but for SMD 19 patients $(63.3 \%)$ were free of pain and 11 patients $(36.7 \%)$ reported grade I. Cavaliere et al.,(2005) reported that coblation less painful. This reflects the potential collateral damage to the surrounding tissues from the high temperature of the cautery as compared to coblation. ${ }^{15}$

According to Tahir Rashid et al., (2015), they showed that snoring improved in $84.88 \%$ and rhinorrhea improved in $47.52 \%$. These results are close to our results as we found that rhinorrhea improved in $77.5 \% .^{16}$

Roje et al., $(2011)^{17}$ found that Improvement was statistically significant for hyposmia ( $\mathrm{p}=0.005)$, while we found that improvement of hyposmia was not statistically significant; for coblation $(\mathrm{p}=0.052)$ and for diathermy $(\mathrm{p}=0.310)$.

Objectively, measuring the size of the inferior turbinate at the widest diameter by CT scan both pre and post-operative was determined in this study significant reduction of the turbinate size using both techniques. No statistical difference between the coblation side and the SMD side can be detected in this study.

The potential advantage of RF tissue ablation with thermocouples for turbinate reduction is the minimally invasive technique using relatively lower power and tissue temperature, which leads to reduced patient pain, decreased frequency and severity of complications. ${ }^{18}$

Woloszko and Golbride (2000) reported that turbinate reduction using the coblation channeling technique is a safe, simple, effective and rapid-less than 1 minute of energy deliveryprocedure. $^{19}$

Our study showed that both SMD and Coblation are effective in inferior turbinate reduction. Coblation is safe and effective in reduction of hypertrophied inferior turbinate, but it is expensive to somewhat in our country as its probe is disposable.

There are no serious intra-operative and postoperative complications except for blood stained discharge and crusting in few patients. Both modalities were well tolerated; however, the coblation showed more improvement and less pain.

Future studies should evaluate longterm outcomes with comparison of both subjective and other objective measures like rhinomanometery and include large scale of patients.

\section{Conclusion:}

SMD and Coblation of inferior turbinate are safe and effective methods of relieving nasal obstruction and other associated symptoms due to inferior turbinate hypertrophy, without affecting the turbinate mucosal function.

There are no serious intra-operative and postoperative complications except for blood stained discharge and crusting in few patients. Both modalities were well tolerated;however, the coblation showed more improvement and less pain. 


\section{Ethical considerations:}

This study was approved by the Institutional Ethics and Research Committee of the Faculty of Medicine, Assiut University, Assiut, Egypt. The whole study was explained to the patients and a written consent was taken.

\section{Conflicts of interest:}

No conflicts of interest were present.

\section{References:}

1- Beckingham R., Philip C. and Jones L. (1988): The nasal valves physiological and clinical study. Journal of Otolaryngology and Otology, 102:1089-1094.

2- Whitaker E. and Menick F. (2002): Rhinoplasty, turbinate reduction. eMedicine Journal, vol. 3 no. 5:435-39.

3- Elwany S., Gaimaee R. and Abdel Fattah H. (1999): Radiofrequency bipolar submucosal diathermy of the inferior turbinates. Am. J. Rhinol.;13(2):145-149.

4- Belov S.V. (2004): Use of HighFrequency Cold Plasma Ablation Technology for Electrosurgery with Minimized Invasiveness, Biomedical Engineering, Vol.38, no2,pp80-85.

5- Utley D.S., Goode R.L. and Hakim I. (1999): Radiofrequency energy tissue ablation for treatment of nasal obstruction secondary to turbinate hypertrophy. Laryngoscope; 109:683-686.

6- Williams H.O.L., Fischer E.W and Goldingwod D.G. (1991): Two stage turbinectomy: Sequestration of the inferior turbinate following submucosal diathermy. Journal Laryngology and Otology; 105:1416.

7- Fradis MD. and Shelton MD. (2002): Inferior turbinectomy versus submucosal diathermy for inferior turbinate hypertrophy. Ann Otol Rhinol Laryngol; 109:1040-1045.

8- Andrich D. (2005): Rasch models for ordered response categories. In B. Everitt \& D. Howell(eds). Encyclopedia of Statistics in Behavioral Science. New York: John Wiley \& Sons. Vol.4: 16981707.

9- Imad H., Javed and Sanaullah (2012): Comparison of submucosal diathermy with partial inferior turbinectomy. A fifty-case study. J Posgard Med Inst 26:9195.

10-Hummel T., Sekinger B., Wolf S.R., Pauli E. and Kobal G. (1997): Olfactory performance assessed by the combined testing of odor identification, odor discrimination and olfactory threshold. Chem Senses. 1997;22: 39-52.

11-Talaat M., El-Sawaby E. and Abdel Baky F. et al. (1987): Submucous diathermy of the inferior turbinates in chronic hypertrophic rhinitis. J LaryngolOtol; 101:452-460.

12-Shah AN, Davey CF, Whitebirck AC, Miller AC, Moens CB (2015): Rapid reverse genetic screening using CRISPR in zipra fish. Nat Methods,2015;12(6):535-40.

13-Casale M., Bottaro V., Sabatino et al. (2014): The efficacy of radiofrequency volumetric tissue reduction of hypertrophied inferior turbinate in simple snoring. Eur Rev Med Pharmacol Sci.18(15):2160-2168.

14-Salzano FA., Renzo Mora, Massimo Dellepiane, IlliasZannis, Giovanni Salzano and Eva Moran Agelo Salami (2009): Radiofrequency, High-Frequency, and Electrocautery Treatments vs Partial Inferior Turbinotomy, Arch 
Otolaryngol Head Neck Surg;Vol 135(8):752-758.

15-Cavaliere M., Mottola G. and Lemma M. (2005): Comparison of the effectiveness and safety of radiofrequency turbinoplasty and traditional surgical technique in treatment of inferior turbinate hypertrophy. Otolaryngol Head Neck Surg.; 133:972-978.

16-Tahir Rashid, Imran Saeed and Salman Baig (2015): Radiofrequency ablation (coblation) treatment of inferior turbinate reduction. PJMHS, Vol. 9, No. 1, 85.

17-Roje Zeljka, Goran Racic and Goran Kardum (2011): Efficacy and safety of inferior turbinate coblation-channeling in the treatment of nasal obstructions. Antropol.35 (2011) 1:143-146.

18-Smith LT., Crrea J. Alex, Kout, Reinisch, (1999): Radiofrequency tissue ablation of the inferior turbinates using a thermocouple feedback electrode, Laryngoscope. 109, (1760-1765).

19-Woloszko J. and Golbride C. (2001): Coblation technology: plasma ablation for Otolaryngology applications, Rep.Arthro Care Corp., Sunnyvale, pp102. 